\title{
Maternal haemoglobin concentrations before and during pregnancy and stillbirth risk: a population-based case-control study

Siavash Maghsoudlou ${ }^{1,2^{*}}$, Sven Cnattingius ${ }^{1}$, Olof Stephansson ${ }^{1,3}$, Mohsen Aarabi ${ }^{4}$, Shahriar Semnani², Scott M. Montgomery ${ }^{1,5,6}$ and Shahram Bahmanyar ${ }^{2,7}$

\begin{abstract}
Background: Results of previous studies on the association between maternal haemoglobin concentration during pregnancy and stillbirth risk are inconclusive. It is not clear if haemoglobin concentration before pregnancy has a role. Using prospectively collected information from pre-pregnancy and antenatal visits, we investigated associations of maternal haemoglobin concentrations before and during pregnancy and haemoglobin dilution with stillbirth risk.

Methods: In a population-based case-control study from rural Golestan, a province in northern Iran, we identified 495 stillbirths (cases) and randomly selected 2,888 control live births among antenatal health-care visits between 2007 and 2009. Using logistic regression, we estimated associations of maternal haemoglobin concentrations, haemoglobin dilution at different stages of pregnancy, with stillbirth risk.

Results: Compared with normal maternal haemoglobin concentration (110-120 g/l) at the end of the second trimester, high maternal haemoglobin concentration $(\geq 140 \mathrm{~g} / \mathrm{l}$ ) was associated with a more than two-fold increased stillbirth risk $(\mathrm{OR}=2.31,95 \% \mathrm{Cl}[1.30-4.10])$, while low maternal haemoglobin concentration $(<110 \mathrm{~g} / \mathrm{l})$ was associated with a $37 \%$ reduction in stillbirth risk. Haemoglobin concentration before pregnancy was not associated with stillbirth risk. Decreased haemoglobin concentration, as measured during pregnancy $(\mathrm{OR}=0.61,95 \% \mathrm{Cl}[0.46,0.80])$, or only during the second trimester $(\mathrm{OR}=0.75,95 \% \mathrm{Cl}[0.62,0.90])$, were associated with reduced stillbirth risk. The associations were essentially similar for preterm and term stillbirths.
\end{abstract}

Conclusions: Haemoglobin concentration before pregnancy is not associated with stillbirth risk. High haemoglobin level and absence of haemoglobin dilution during pregnancy could be considered as indicators of a high-risk pregnancy.

Keywords: Stillbirth, Maternal anaemia, Haemoglobin concentration, Haemoglobin dilution, Adverse pregnancy outcome

\section{Background}

Results of previous studies on associations between maternal haemoglobin concentration and risks of preterm birth, low birth weight, small for gestational age, and stillbirth are inconclusive [1,2]. We and others have previously reported that both low and high haemoglobin concentration during pregnancy may increase stillbirth risk [2-4]. Yet, other studies have found that increased

\footnotetext{
* Correspondence: Siavash.Maghsoudlou@ki.se

${ }^{1}$ Clinical Epidemiology Unit, Department of Medicine Solna, Karolinska Institute, Karolinska Hospital, SE-171 76 Stockholm, Sweden

${ }^{2}$ Faculty of Medicine, Golestan University of Medical Sciences, Gorgan, Iran Full list of author information is available at the end of the article
}

stillbirth risk is restricted to women with either low [5] or high [6] haemoglobin values.

During pregnancy, there is significant change in maternal haemostatic profile [7], including haemoglobin dilution due to the expanding serum component of the blood [8]. Disruption in this process, possibly due to pathology in early pregnancy [9], seems to be associated with adverse pregnancy outcomes [2]. However, it is not clear if haemoglobin concentration before pregnancy modifies this association.

In the Golestan province in northern Iran, the primary health care organization provides modern antenatal and obstetric care to virtually all pregnant women. In the rural part of the province, most pregnancies are planned 
and most women have, following the recommendations of the Alma Ata conference, a pre-pregnancy visit followed by several antenatal visits [10]. Information on maternal haemoglobin concentrations measured before pregnancy and repeatedly during pregnancy is routinely recorded.

In this population-based case-control study of stillbirth from the rural area of the Golestan province in northern Iran, we studied associations of haemoglobin concentrations before and during pregnancy with stillbirth risk, and also studied associations of maternal haemoglobin dilution (average weekly change in haemoglobin concentration) during the first and second trimester of pregnancy with stillbirth risk.

\section{Methods}

\section{Study setting}

The study was performed in rural areas of the Golestan province, in northeast Iran. Golestan province has a population of approximately 1,700,000 inhabitants (50\% living in rural areas), and has approximately 17,000 births annually. The public health care system in Iran specifies that each rural health house is responsible for providing care and recording information before and during pregnancy and after delivery. Blood profile and other laboratory data are routinely assessed at the prepregnancy visit and twice during pregnancy. Such information is prospectively recorded in the family health files held by approximately 600 rural health houses.

\section{Study design}

The study design has been described in full elsewhere [11]. All identified singleton stillbirths in the rural areas of Golestan Province between 2007 and 2009 were selected as cases. Stillbirth was defined as delivery of a baby without any vital signs at 28 weeks of gestation or later. We identified 501 singleton stillbirths, and after excluding stillbirths without any maternal blood haemoglobin concentration records during pregnancy, 495 stillbirths were selected as cases. Controls were selected using a stratified random sampling method. As growth rate vary between regions of Golestan province, we defined each region as a stratum and calculated the sample size for each stratum. The proportion of registered pregnancies selected was based on the population growth rate of the region. Each pregnancy had the same probability to be selected. We selected controls using random digits generated by computer. We aimed to have at least five controls per case after excluding births before 28 gestational weeks, multiple births, and stillbirths. The control group comprised 2,888 live singleton births with a gestational age of at least 28 completed weeks.

Information on maternal and pregnancy characteristics were collected from medical records by midwifes working at the health centres. Data were abstracted from pre-pregnancy, pregnancy and delivery records, and information was entered using Access software by ten specially trained medical students. Each record, including information on the mother, children and spouse, received a unique code at the time of data collection and these codes were used during data entry to identify individuals and make it possible to analyse the data anonymously. The measurement of socioeconomic circumstances was based on husband's profession (unskilled manual worker, skilled manual worker, self-employed, farmer, other occupations, and unemployed). Self-reported information on current or previous smoking and opium use was also collected. As a quality control, we collected and computerized $10 \%$ of the data a second time. The variables that had more than $5 \%$ mismatches were recollected and the data reentered for all study subjects. If the data for a health centre had more than $5 \%$ mismatches, all data were recollected and re-entered for that centre.

Based on the "Iranian National Antenatal Care" protocols in the primary health care system, laboratory testing (included complete blood count test, blood biochemistry profile, and urine analysis) was performed twice during pregnancy: at 6 to 10 and at 26 to 30 gestational weeks.

The mean gestational ages for the first and second haemoglobin concentration measurements were 9 weeks and 28 weeks for both cases and controls. Haemoglobin dilution during the second trimester of pregnancy was calculated as the difference between blood haemoglobin concentration at the first and last measurement during pregnancy, divided by the time period (completed weeks) between the two measurements (mean change in haemoglobin concentration per gestational week). Observations with a time interval of less than three weeks between two haemoglobin measurements were excluded from the analysis of haemoglobin dilution $(n=3)$.

Among all cases $(n=495)$ and controls $(n=2,888), 158$ cases and 1,225 controls also had a recorded blood haemoglobin concentration during the year before pregnancy. For this group we also estimated haemoglobin dilution during pregnancy, defined as the difference between the pre-pregnancy and the last pregnancy measurement of blood haemoglobin concentration, divided by gestational age (in completed weeks) at the last measurement.

Gestational age was based on the time interval between date of delivery and date of the first day of the last menstrual period. Preterm delivery was defined as a delivery before 37 completed weeks. As a proxy measure for foetal growth restriction, we used small for gestational age (SGA), which was defined as a birth weight below the $10^{\text {th }}$ percentile (in the control group) for gestational age (week) and sex. Because of the limited 
number of preterm births in the control group, we could not estimate appropriate cut off limits for SGA in preterm deliveries. Maternal blood pressure was measured before pregnancy, at least 8 times during pregnancy and after delivery. Hypertension was defined as a measured systolic blood pressure $\geq 140$ and/or diastolic blood pressure $\geq 90$ during each trimester of pregnancy.

The study was approved by the Research Ethics Committee of Golestan University of Medical Sciences and the Karolinska Institutet regional ethics committee. The ethical committees did not require written informed consent for participation in the study.

\section{Statistical analysis}

We used univariable and multivariate logistic regression models to estimate odds ratios (ORs) and $95 \%$ confidence intervals (CIs) for the associations of maternal haemoglobin concentrations, haemoglobin dilution, with stillbirth risk. As the outcome is rare in both exposed and unexposed mothers, the odds ratio approximates the risk ratio and the results are described in terms of risk ratio throughout the paper. The multivariate models were adjusted for maternal age, pre-pregnancy body mass index (BMI), height, gestational age at the first haemoglobin measurement, parity $(0,1-2,>2)$, smoking status, region of residence, and husband's profession. We also investigated possible nonlinear effects of age and BMI by introducing age squared and BMI squared into the adjusted model. However, these variables had not notable effects and were therefore not included in the final models.

Pregnancy-induced hypertensive diseases are related to both stillbirth risk [12] and haemoglobin concentration during pregnancy [13]. Information on preeclampsia or eclampsia was not available, but we performed a sensitivity analysis after excluding all subjects with a record of hypertension during pregnancy.

We estimated odds ratios for stillbirth associated with maternal haemoglobin concentrations before pregnancy, in the first trimester, and in the second trimester of pregnancy. We estimated the risks using both maternal haemoglobin concentration as a continuous variable (gram per litter $[\mathrm{g} / \mathrm{l}]$ ), and as a four-category measure $(<110,110-120,120-139$, and $\geq 140 \mathrm{~g} / \mathrm{l})$. We also estimated odds ratios for stillbirth associated with haemoglobin dilution in each gestational week: a) during pregnancy $(>0.78,0.78-0.01$, and $\leq 0.00 \mathrm{~g} / \mathrm{l})$, and b) during the second trimester of pregnancy $(>0.78,0.78-0.01$, and $\leq 0.00 \mathrm{~g} / \mathrm{l})$. The haemoglobin categories were based on tertiles of the distribution in the control group.

A multiple imputation method was used to provide data where there were missing values for maternal age (32 among controls) and husband's profession (16 among cases and 79 among controls) [14]. The MI procedure
(SAS software) with five imputations was used. We also performed a sensitivity analysis by restricting the analysis to observations without any missing data.

SAS software version 9.3 was used for analysing the data.

\section{Results}

Maternal characteristics of cases and controls are presented in the Table 1. Associations of the maternal haemoglobin concentrations with risk of stillbirth are presented in Table 2. Maternal haemoglobin concentration measured before pregnancy was not associated with stillbirth risk. Compared with normal maternal haemoglobin values (110-120 g/l) at the end of the first trimester, high haemoglobin values $(\geq 140 \mathrm{~g} / \mathrm{l})$ were associated with a $36 \%$ increased risk of stillbirth. Compared with normal haemoglobin values at the second trimester of pregnancy, high maternal haemoglobin values were associated with a more than two-fold increased risk of stillbirth, and low haemoglobin concentration $(\leq 110 \mathrm{~g} / \mathrm{l})$ was associated with a reduced stillbirth risk. We also estimated associations between the maternal haemoglobin concentrations and risk of stillbirth stratified by gestational age (preterm and term stillbirth), which showed no notable differences in the results (Additional file 1).

The associations between level of haemoglobin dilution and stillbirth risk are shown in Table 3. Compared with mothers who did not have any change in haemoglobin concentration during the second trimester, those with decreased haemoglobin concentration had a reduced stillbirth risk. For the subsample where information on pre-pregnancy haemoglobin concentration was available, we also estimated haemoglobin dilution during pregnancy (from before pregnancy to last measurement during pregnancy). Compared with those who did not have any change in haemoglobin concentration during pregnancy, those with decreased haemoglobin concentration had a reduced stillbirth risk. There was a dose-response association between haemoglobin dilution as an exposure and stillbirth risk, both in the analysis of the second trimester and in the analysis of pregnancy.

We also performed a sensitivity analysis after excluding all pregnancies with a record of hypertension (systolic blood pressure $\geq 140$ and/or diastolic blood pressure 290 ) during pregnancy. After excluding 36 cases and 102 controls with hypertensive disorders, the results were virtually unchanged (data not shown).

Table 4 shows associations between average weekly change in haemoglobin concentration and risks of preterm and term stillbirth. There was no substantial difference between risks for term and preterm stillbirth using the categorical variable: higher levels of haemoglobin dilution were associated with lower risk of preterm stillbirth and there was a dose response association ( $p$ for 
Table 1 Maternal characteristics for 495 stillbirths and 2,888 live singleton births in Golestan, Iran

\begin{tabular}{|c|c|c|}
\hline & Cases & Controls \\
\hline & n (\%) & n (\%) \\
\hline \multicolumn{3}{|c|}{ Mother's age, year } \\
\hline$\leq 19$ & $72(14.5)$ & $363(12.6)$ \\
\hline $20-24$ & $127(25.7)$ & $865(30.0)$ \\
\hline $25-29$ & $138(27.9)$ & $760(26.3)$ \\
\hline $30-34$ & 92 (18.6) & $589(20.4)$ \\
\hline$\geq 35$ & $66(13.3)$ & $279(9.7)$ \\
\hline Missing & $0(0)$ & $32(1.1)$ \\
\hline \multicolumn{3}{|c|}{ Body mass index } \\
\hline$<18.5$ & $39(7.9)$ & $200(6.9)$ \\
\hline 18.5 to $<25$ & $180(36.4)$ & $1,426(49.4)$ \\
\hline 25 to $<30$ & $117(23.6)$ & $655(22.7)$ \\
\hline 30 to $<35$ & $56(11.3)$ & $230(8.0)$ \\
\hline$\geq 35$ & $26(5.3)$ & $60(2.1)$ \\
\hline Missing & $77(15.6)$ & $317(11.0)$ \\
\hline \multicolumn{3}{|c|}{ Mother's height, cm } \\
\hline$<150$ & $48(9.7)$ & $192(6.6)$ \\
\hline $150-154$ & $116(23.4)$ & $590(20.4)$ \\
\hline $155-159$ & $152(30.7)$ & $921(31.9)$ \\
\hline $160-164$ & $55(11.1)$ & 479 (16.6) \\
\hline$\geq 165$ & $47(9.5)$ & $389(13.5)$ \\
\hline Missing & 77 (15.6) & $317(11.0)$ \\
\hline \multicolumn{3}{|l|}{ Parity } \\
\hline 0 & $256(51.7)$ & $1,140(39.5)$ \\
\hline $1-2$ & $192(38.8)$ & $1,338(46.3)$ \\
\hline$\geq 3$ & $32(6.5)$ & $189(6.5)$ \\
\hline Missing & $15(3.0)$ & $221(7.7)$ \\
\hline
\end{tabular}

Pregnancy induced hypertension

$$
459 \text { (92.7) }
$$

$2,786(96.5)$

$36(7.3)$

$102(3.5)$

Smoking

$\begin{array}{lll}\text { No } & 488(98.6) & 2,803(97.1) \\ \text { Yes } & 7(1.4) & 85(2.9) \\ \begin{array}{l}\text { Husband's profession } \\ \text { Unemployed }\end{array} & 16(3.2) & 76(2.6) \\ \text { Non skill worker } & 206(41.6) & 1,318(45.6) \\ \text { Skill worker } & 55(11.1) & 275(9.5) \\ \text { Self-employed } & 78(15.8) & 327(11.3) \\ \text { Farmer } & 79(16.0) & 547(18.9) \\ \text { Other } & 44(8.9) & 266(9.2) \\ \text { Missing } & 17(3.4) & 79(2.7)\end{array}$

Table 1 Maternal characteristics for 495 stillbirths and 2,888 live singleton births in Golestan, Iran (Continued)

\begin{tabular}{lll}
\hline Haemoglobin concentration before pregnancy (g/l) & \\
Mean (SD) & $126.3(10.4)$ & $125.7(11.4)$ \\
Median (Range) & $130.0(100-150)$ & $120.0(80-160)$ \\
Haemoglobin concentration at first trimester (g/l) & \\
Mean (SD) & $124.5(12.3)$ & $122.7(11.7)$ \\
Median (Range) & $120.0(80$ to 170) & $120.0(70$ to 160) \\
Haemoglobin concentration at end of second trimester (g/l) \\
Mean (SD) & $117.1(11.6)$ & $113.5(11.3)$ \\
Median (Range) & $120.0(80-150)$ & $110.0(70-170)$ \\
Region & & \\
Aghghala & $51(10.3)$ & $183(13.1)$ \\
Aliabad & $28(5.7)$ & $142(4.9)$ \\
Azadshahr & $32(6.5)$ & $114(3.9)$ \\
Bandargaz & $7(1.4)$ & $115(4.0)$ \\
Galikesh & $23(4.6)$ & $104(3.6)$ \\
Gomishan & $37(7.5)$ & $524(18.1)$ \\
Gonbad & $130(26.3)$ & $284(9.8)$ \\
Gorgan & $15(3.0)$ & $361(12.5)$ \\
Kalaleh & $65(13.1)$ & $84(2.9)$ \\
Kordkoy & $14(2.8)$ & $168(5.8)$ \\
Maraveh & $37(7.5)$ & $235(8.1)$ \\
Minoodasht & $23(4.6)$ & $102(3.5)$ \\
Ramian & $16(3.2)$ & $95.4)$ \\
Torkaman & & \\
\hline & & \\
& &
\end{tabular}

trend $<0.01)$. For term stillbirth, we observed a statistically significant $25 \%$ risk reduction for an average of one $g / l$ weekly change in haemoglobin during the second trimester. For preterm stillbirth, the corresponding point estimate was identical, but not statistically significant (Table 4).

Table 5 shows associations between average weekly change in haemoglobin concentration and stillbirth stratified by SGA stillbirths and non-SGA stillbirths in term deliveries. Using the measure of change in haemoglobin concentration as a continuous variable, we observed a $40 \%$ risk reduction of SGA stillbirth for each g/l weekly change in haemoglobin during the second trimester. Haemoglobin dilution was not associated with a reduced risk of non-SGA term stillbirth. Restricting analyses to observations without any missing data did not change the results notably.

\section{Discussion}

This population-based case-control study showed that haemoglobin concentration before pregnancy was not associated with stillbirth risk. High and low haemoglobin 
Table 2 Haemoglobin concentration and the risk of stillbirth

\begin{tabular}{|c|c|c|c|c|}
\hline & \multirow{2}{*}{$\begin{array}{l}\text { Cases } \\
\text { n (\%) }\end{array}$} & \multirow{2}{*}{$\begin{array}{l}\text { Controls } \\
\text { n (\%) }\end{array}$} & \multicolumn{2}{|c|}{ Odds Ratio (95 \% Confidence Interval) } \\
\hline & & & Crude & Adjusted $^{a}$ \\
\hline \multicolumn{5}{|c|}{ Haemoglobin concentration before pregnancy (g/l) } \\
\hline$<110$ & $4(2.5)$ & $31(2.5)$ & $1.04(0.36-3.04)$ & $1.23(0.39-3.84)$ \\
\hline $110-120$ & $72(45.6)$ & $582(47.5)$ & Reference & Reference \\
\hline $121-139$ & $49(31.0)$ & $360(29.4)$ & $1.10(0.75-1.61)$ & $0.97(0.64-1.47)$ \\
\hline$\geq 140$ & $33(20.9)$ & $252(21.0)$ & $1.06(0.68-1.64)$ & $0.83(0.52-1.34)$ \\
\hline Continuous & $158(100)$ & $1,225(100)$ & $1.00(0.99-1.02)$ & $1.00(0.98-1.01)$ \\
\hline \multicolumn{5}{|c|}{ Haemoglobin concentration at first trimester ( $\mathrm{g} / \mathrm{l})$ (gestational age weeks between 6 to 10 ) } \\
\hline$<110$ & $26(5.3)$ & $181(6.5)$ & $0.91(0.59-1.40)$ & $0.87(0.55-1.37)$ \\
\hline $110-120$ & $223(46.1)$ & $1,411(50.5)$ & Reference & Reference \\
\hline $121-139$ & $152(31.4)$ & $834(30.0)$ & $1.45(0.92-1.44)$ & $1.18(0.94-1.49)$ \\
\hline$\geq 140$ & $83(17.1)$ & $366(13.1)$ & $1.43(1.09-1.89)$ & $1.36(1.01-1.81)$ \\
\hline Continuous & $484(100)$ & $2,792(100)$ & $1.01(1.00-1.02)$ & $1.01(1.00-1.02)$ \\
\hline \multicolumn{5}{|c|}{ Haemoglobin concentration at end of second trimester(g/l) (gestational age weeks between 26 to 30) } \\
\hline$<110$ & $37(14.0)$ & $523(21.2)$ & $0.64(0.44-0.92)$ & $0.63(0.43-0.92)$ \\
\hline $110-120$ & $180(65.2)$ & $1,618(65.6)$ & Reference & Reference \\
\hline $121-139$ & $40(14.4)$ & $268(10.9)$ & $1.34(0.93-1.93)$ & $1.19(0.81-1.74)$ \\
\hline$\geq 140$ & $18(6.4)$ & $59(2.4)$ & $2.74(1.58-4.75)$ & $2.31(1.30-4.10)$ \\
\hline Continuous & 275 (100) & $2,468(100)$ & $1.03(1.02-1.04)$ & $1.03(1.01-1.04)$ \\
\hline
\end{tabular}

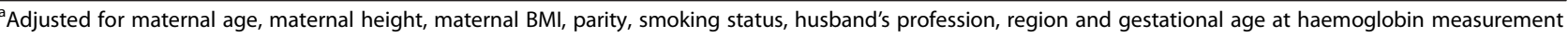

concentrations at the end of the second trimester were associated with an increased and a reduced stillbirth risk, respectively. Decreased haemoglobin concentration, during the entire pregnancy or during the second trimester, was also associated with reduced stillbirth risk.

Our findings are consistent with other studies, reporting positive associations between increasing maternal haemoglobin levels in early $[2,15]$ or late pregnancy [16] and risk of stillbirth or other adverse outcomes
[13, 17-19]. During pregnancy, plasma renin activity increases $[9,20]$ and the atrial natriuretic peptide levels decrease to meet demands of new vascular beds [21, 22]. High maternal erythropoietin secretion during pregnancy causes an increase in red blood cell mass. However, this increase is less than the change in the plasma volume, which causes a 10 to 20 gram decrease in haemoglobin concentration per litre plasma at the end of the second trimester in normal pregnancy

Table 3 Haemoglobin dilution and the risk of stillbirth

\begin{tabular}{|c|c|c|c|c|}
\hline & \multirow{2}{*}{$\begin{array}{l}\text { Cases } \\
\text { n (\%) }\end{array}$} & \multirow{2}{*}{$\begin{array}{l}\text { Controls } \\
\text { n (\%) }\end{array}$} & \multicolumn{2}{|c|}{ Odds Ratio (95 \% Confidence Interval) } \\
\hline & & & Crude & Adjusted $^{a}$ \\
\hline \multicolumn{5}{|c|}{ Haemoglobin dilution during second trimester of pregnancy (g/l) } \\
\hline$>0.78$ & $70(26.7)$ & $765(33.8)$ & $0.57(0.42-0.78)$ & $0.54(0.39-0.74)$ \\
\hline $0.78-0.01$ & $73(27.9)$ & $750(33.2)$ & $0.61(0.45-0.83)$ & $0.62(0.45-0.85)$ \\
\hline $0.00 \leq$ & $119(45.4)$ & $745(33.0)$ & Reference & Reference \\
\hline$P$ for trend & & & & $<0.0001$ \\
\hline Continuous & $262(100)$ & $2,260(100)$ & $0.76(0.63-0.92)$ & $0.75(0.62-0.90)$ \\
\hline \multicolumn{5}{|c|}{ Haemoglobin dilution during pregnancy $(\mathrm{g} / \mathrm{l})$} \\
\hline$>0.69$ & $31(20.0)$ & $392(33.1)$ & $0.33(0.21-0.51)$ & $0.33(0.21-0.52)$ \\
\hline $0.69-0.01$ & $38(24.5)$ & $430(36.3)$ & $0.37(0.25-0.56)$ & $0.42(0.27-0.66)$ \\
\hline $0.00 \leq$ & $86(55.5)$ & $361(30.5)$ & Reference & Reference \\
\hline$P$ for trend & & & & $<0.0001$ \\
\hline Continuous & 155 (100) & $1,183(100)$ & $0.58(0.45-0.74)$ & $0.61(0.46-0.80)$ \\
\hline
\end{tabular}

${ }^{2}$ Adjusted for maternal age, maternal height, maternal BMl, parity, gestational age at first haemoglobin measurement, smoking status, husband's profession, and region 
Table 4 Haemoglobin dilution and risks of preterm and term stillbirth

\begin{tabular}{|c|c|c|c|c|c|c|}
\hline & \multicolumn{3}{|c|}{ Preterm stillbirth } & \multicolumn{3}{|l|}{ Term stillbirth } \\
\hline & \multirow{2}{*}{$\begin{array}{l}\text { Cases }(n=81) \\
\mathrm{n}(\%)\end{array}$} & \multirow{2}{*}{$\begin{array}{l}\text { Controls }(n=2,260) \\
\text { n (\%) }\end{array}$} & \multirow{2}{*}{$\begin{array}{l}\text { Odds ratio }(95 \% \mathrm{Cl})^{\mathrm{b}} \\
\mathrm{n}(\%)\end{array}$} & \multirow{2}{*}{$\begin{array}{l}\text { Cases }(n=181) \\
\mathrm{n}(\%)\end{array}$} & \multirow{2}{*}{$\begin{array}{l}\text { Controls }(n=2,105) \\
\mathrm{n}(\%)\end{array}$} & \multirow{2}{*}{$\begin{array}{l}\text { Odds ratio } \\
(95 \% \text { Cl) })^{b}\end{array}$} \\
\hline & & & & & & \\
\hline \multicolumn{7}{|c|}{ Haemoglobin dilution during second trimester of pregnancy (g/l) } \\
\hline$>0.78$ & $22(27.6)$ & $765(33.8)$ & $0.49(0.28-0.84)$ & $48(26.5)$ & $716(34.0)$ & $0.55(0.38-0.81)$ \\
\hline $0.78-0.01$ & $20(24.7)$ & $750(33.2)$ & $0.50(0.28-0.87)$ & $53(29.3)$ & $701(33.3)$ & $0.67(0.46-0.97)$ \\
\hline $0.00 \leq$ & $39(48.1)$ & $745(33.0)$ & Reference & $80(44.2)$ & $688(32.7)$ & Reference \\
\hline$P$ for trend & & & $<0.01$ & & & $<0.01$ \\
\hline Continuous & $81(100)$ & $2,260(100)$ & $0.75(0.54-1.06)$ & $181(100)$ & $2,105(100)$ & $0.75(0.61-0.93)$ \\
\hline
\end{tabular}

${ }^{a}$ Adjusted for: maternal age, maternal height, maternal BMI, parity, gestational age at first haemoglobin measurement, history of smoking, husband's profession, and region

${ }^{\mathrm{b}} \mathrm{OR}$ denotes Odds ratios and $\mathrm{Cl}$ denotes confidence intervals

[7]. High blood haemoglobin levels may be a consequence of disturbance in the physiology of expanding the serum component of the maternal blood during pregnancy $[23,24]$.

We also observed that decreased haemoglobin concentration during pregnancy was associated with lower risk of stillbirth, regardless of initial haemoglobin level or time of the change in haemoglobin concentration. This protective effect was also observed in previous studies on stillbirth [2], preeclampsia [25], and low birth weight $[25,26]$. However, previous studies did not have prepregnancy data to investigate the possible role of haemoglobin concentration before pregnancy. The association was essentially similar between preterm and term stillbirths, and if anything, more marked among SGA stillbirths in term pregnancies. These findings, which are consistent with the results of a Swedish study [2], may indicate that the risk of stillbirth related to high haemoglobin concentration during pregnancy might be associated with impaired foetal growth. We did not have enough data to investigate risks stillbirth risks associated with impaired foetal growth in preterm pregnancies or stillbirths with malformations.

Preeclampsia is associated with both stillbirth risk [12] and haemoglobin concentration during pregnancy [13] and this disorder could be an intermediate factor. As information on preeclampsia or eclampsia was not available, we reanalysed the data after excluding all subjects with a record of hypertension during pregnancy. We observed no notable change in the results. This is in contrast with the results of a Swedish study [2] in which the stillbirth-related risks associated with a high haemoglobin concentration increased when women with preeclampsia or eclampsia were excluded.

To the best of our knowledge, there are no published data on the association between haemoglobin concentration prior to pregnancy and risk of stillbirth. The lack of association between haemoglobin concentration before pregnancy and stillbirth in this study could be because women with a low haemoglobin concentration receive pharmacological treatment before pregnancy. Based on routines in the primary health care system in Iran, more than $90 \%$ of pregnant women receive iron and other micro-supplements after the 16th week of pregnancy. Moreover, women of reproductive age undergo screening to identify and treat iron deficiency anaemia, particularly before pregnancy [10] which can increase haemoglobin concentration [27]. This practise eliminates to a large extent the possible effects of iron deficiency in our study. Iron deficiency can be a major contributory

Table 5 Haemoglobin dilution and risks of SGA and Non-SGA in term stillbirth

\begin{tabular}{|c|c|c|c|c|c|c|}
\hline & \multicolumn{3}{|l|}{ SGA stillbirth } & \multicolumn{3}{|c|}{ Non-SGA stillbirth } \\
\hline & \multirow{2}{*}{$\begin{array}{l}\text { Cases }(n=55) \\
\mathrm{n}(\%)\end{array}$} & \multirow{2}{*}{$\begin{array}{l}\text { Controls }(n=215) \\
\mathrm{n}(\%)\end{array}$} & \multirow{2}{*}{$\begin{array}{l}\text { Odds ratio } \\
(95 \% \mathrm{Cl})^{\mathrm{b}}\end{array}$} & \multirow{2}{*}{$\begin{array}{l}\text { Cases }(n=75) \\
\mathrm{n}(\%)\end{array}$} & \multirow{2}{*}{$\begin{array}{l}\text { Controls }(n=1,858) \\
\mathrm{n}(\%)\end{array}$} & \multirow{2}{*}{$\begin{array}{l}\text { Odds ratio } \\
(95 \% \mathrm{Cl})^{\mathrm{b}}\end{array}$} \\
\hline & & & & & & \\
\hline \multicolumn{7}{|c|}{ Haemoglobin dilution during second trimester of pregnancy (g/l) } \\
\hline$>0.78$ & $12(26.4)$ & $66(34.0)$ & $0.48(0.19-1.22)$ & $20(26.7)$ & $639(34.4)$ & $0.62(0.34-1.11)$ \\
\hline $0.78-0.01$ & $18(25.5)$ & $67(33.3)$ & $1.01(0.43-2.39)$ & $26(34.7)$ & $621(33.4)$ & $0.87(0.50-1.52)$ \\
\hline $0.00 \leq$ & $25(48.1)$ & $82(32.6)$ & Reference & $29(38.7)$ & $598(32.2)$ & Reference \\
\hline Continuous & $55(100)$ & $215(100)$ & $0.59(0.36-0.97)$ & $75(100)$ & $1,858(100)$ & $0.95(0.68-1.33)$ \\
\hline
\end{tabular}

${ }^{a}$ Adjusted for: maternal age, maternal height, maternal BMI, parity, gestational age at first haemoglobin measurement, history of smoking, husband's profession, and region

${ }^{\mathrm{b}} \mathrm{OR}$ denotes Odds ratios and $\mathrm{Cl}$ denotes confidence intervals 
factor to both haemoglobin dilution and serious maternal anaemia, [7] which might increase risk of adverse pregnancy outcomes such as preterm birth and low birth weight [1]. A recent meta-analysis showed that prenatal iron use is associated with a significant increase in birth weight and reduction in risk of low birth weight [28]. However, prenatal daily iron supplement intake might also be associated with risk of higher haemoglobin concentration during pregnancy [29]. Therefore, it is questionable whether women with normal blood values benefit from taking iron supplements [30].

Strengths of the study include the use of prospectively collected information from antenatal visits. We included all cases and randomly selected controls with information on maternal blood profile, and extracted prospectively recorded information from family health records, which minimizes risks of selection and recall bias. This study was conducted in rural areas of Golestan province, where most pregnancies are planned, and some $97 \%$ of pregnant women are in contact with the primary health care system.

This study has also some potential limitations. Maternal blood profile was tested in different laboratories which may had different methods and accuracy. As recorded haemoglobin concentrations were rounded to the nearest half unit, we did not have information on exact values. The number of women with a very low haemoglobin concentration was small and we could not estimate the risk of stillbirth among this group. As stillbirth was defined as delivery of a baby without any vital signs at 28 weeks of gestation or later, we did not have any information on very preterm stillbirth (less 28 weeks gestational age). This helps to explain the low proportion of preterm stillbirths in our study. Smoking is culturally not accepted in rural area of Iran, and some women may have not have reported history of smoking accurately. As we used prospectively collected information before and during pregnancy, possible misclassification of smoking status would be non-differential, and if anything, shift the association toward the null. Opium use exists among women of childbearing age in Iran [31]. In Golestan province most of the married women (more than $90 \%$ ) are housewives and we did not have any information about educational level of the mothers. Another limitation is that the husband's profession, which is used as measure of socioeconomic conditions for families, may not be sufficiently discriminatory. We restricted our study to pregnancies in rural areas of the Golestan province and there may be concern regarding generalizability of the results. Exclusion of those with missing haemoglobin values might cause selection bias. Finally, we did not have any data to determine the cause of the stillbirth, specifically genetic testing, autopsy, or placental pathology or congenital defects; therefore we could not investigate difference in the association between haemoglobin concentration and stillbirth by malformation.

\section{Conclusions}

In conclusion, this study showed that haemoglobin concentration before pregnancy was not associated with stillbirth risk. This study also provides evidence that elevated maternal haemoglobin level during pregnancy is a risk factor for stillbirth, and low haemoglobin level is inversely associated with stillbirth. High haemoglobin level and absence of haemoglobin dilution during pregnancy could be considered as indicators of a high-risk pregnancy, regardless of haemoglobin concentration before pregnancy.

\section{Additional file}

Additional file 1: Haemoglobin concentration and the risk of term and preterm stillbirth. (DOC $19 \mathrm{~kb}$ )

\section{Abbreviations}

$\mathrm{BMI}$, body mass index; $\mathrm{Cl}$, confidence interval; $\mathrm{G} / \mathrm{L}$, germ per litter; Non-SGA, non small for gestational age; OR, odds ratio; SGA, small for gestational age.

\section{Acknowledgements \\ We are indebted to the members of the primary health care system of Golestan University of medical sciences, particularly maternal health care units in rural area of Golestan in north of Iran.}

\section{Funding}

This work was entirely funded by internal funding of Karolinska Institute.

\section{Authors' contributions}

SC and SB contributed to the planning and design of the epidemiological study. SM, SB, MA, and SS contributed in data collection and provided access to the data. SM, SC, and SB were involved in the review of the raw data and directly involved in the analysis. SC, SB, SMM, and OS supervised this process and provided analytical feedback based on aggregated results. SM, SC, MA, SMM, OS, and SB were directly involved to the interpreting the results and provided substantive review and commentary on multiple drafts. SM prepared the draft of manuscript. All authors read and approved the final manuscript.

\section{Competing interests}

The authors declare that they have no competing interests.

\section{Ethics approval and consent to participate}

Ethics approval for this study was obtained from the ethical committees of Golestan University of medical sciences, Iran (35/2633-p/g, 17 January 2011) and Karolinska Institutet, Sweden (2011/1657-31/3).

\section{Author details}

${ }^{1}$ Clinical Epidemiology Unit, Department of Medicine Solna, Karolinska Institute, Karolinska Hospital, SE-171 76 Stockholm, Sweden. ${ }^{2}$ Faculty of Medicine, Golestan University of Medical Sciences, Gorgan, Iran. ${ }^{3}$ Division of Obstetrics and Gynecology, Department of Women's and Children's Health, Karolinska University Hospital and Institute, Stockholm, Sweden. ${ }^{4}$ Faculty of Medicine, Mazandaran University of Medical Sciences, Sari, Iran. ${ }^{5} \mathrm{Clinical}$ Epidemiology and Biostatistics, School of Medical Sciences, Örebro University, Örebro, Sweden. ${ }^{6}$ Research Department of Epidemiology and Public Health, University College London, London, UK. ${ }^{7}$ Clinical Epidemiology Unit \& Center for Pharmacoepidemiology, Department of Medicine, Karolinska Institute, Solna, Sweden. 
Received: 18 June 2015 Accepted: 27 May 2016

Published online: 03 June 2016

\section{References}

1. Sukrat B, Wilasrusmee C, Siribumrungwong B, McEvoy M, Okascharoen C, Attia J, et al. Hemoglobin concentration and pregnancy outcomes: a systematic review and meta-analysis. Biomed Res Int. 2013;2013:769057. doi:10.1155/2013/769057.

2. Stephansson O, Dickman PW, Johansson A, Cnattingius S. Maternal hemoglobin concentration during pregnancy and risk of stillbirth. JAMA. 2000:284(20):2611-7.

3. Gonzales GF, Steenland K, Tapia V. Maternal hemoglobin level and fetal outcome at low and high altitudes. Am J Physiol Regul Integr Comp Physiol. 2009;297(5):R1477-85. doi:10.1152/ajpregu.00275.2009.

4. Gonzales GF, Tapia V, Gasco M, Carrillo CE. Maternal hemoglobin concentration and adverse pregnancy outcomes at low and moderate altitudes in Peru. J Matern Fetal Neonatal Med. 2012;25(7):1105-10. doi:10.3109/14767058.2011.623200.

5. Zhang Q, Ananth CV, Rhoads GG, Li Z. The impact of maternal anemia on perinatal mortality: a population-based, prospective cohort study in China. Ann Epidemiol. 2009;19(11):793-9. doi:10.1016/j.annepidem.2009.06.002.

6. Gaillard R, Eilers PH, Yassine S, Hofman A, Steegers EA, Jaddoe WW. Risk factors and consequences of maternal anaemia and elevated haemoglobin levels during pregnancy: a population-based prospective cohort study. Paediatr Perinat Epidemiol. 2014;28(3):213-26. doi:10.1111/ppe.12112.

7. Chandra S, Tripathi AK, Mishra S, Amzarul M, Vaish AK. Physiological changes in hematological parameters during pregnancy. Indian J Hematol Blood Transfus. 2012;28(3):144-6. doi:10.1007/s12288-012-0175-6.

8. Bernstein IM, Ziegler W, Badger GJ. Plasma volume expansion in early pregnancy. Obstet Gynecol. 2001;97(5 Pt 1):669-72

9. Chapman AB, Zamudio S, Woodmansee W, Merouani A, Osorio F, Johnson A et al. Systemic and renal hemodynamic changes in the luteal phase of the menstrual cycle mimic early pregnancy. Am J Phys. 1997;273(5 Pt 2):F777-82.

10. Rashidian AKA, Khabiri R, Khodayari-Moez E, Elahi E, Arab M, Radaie Z. Islamic Republic of Iran's Multiple Indicator Demograpphic and Healh Survey (IrMIDHS). 2010. p. 2010.

11. Maghsoudlou S, Cnattingius S, Aarabi M, Montgomery SM, Semnani S, Stephansson $\mathrm{O}$, et al. Consanguineous marriage, prepregnancy maternal characteristics and stillbirth risk: a population-based case-control study. Acta Obstet Gynecol Scand. 2015;94(10):1095-101. doi:10.1111/aogs.12699.

12. Flenady V, Koopmans L, Middleton P, Froen JF, Smith GC, Gibbons K, et al. Major risk factors for stillbirth in high-income countries: a systematic review and meta-analysis. Lancet. 2011;377(9774):1331-40. doi:10.1016/S01406736(10)62233-7.

13. Phaloprakarn C, Tangjitgamol S. Impact of high maternal hemoglobin at first antenatal visit on pregnancy outcomes: a cohort study. J Perinat Med. 2008;36(2):115-9. doi:10.1515/JPM.2008.018.

14. Rubin DB, Schenker N. Multiple Imputation in Health-Care Databases - an Overview and Some Applications. Stat Med. 1991;10(4):585-98. doi:10.1002/ sim.4780100410.

15. Murphy JF, O'Riordan J, Newcombe RG, Coles EC, Pearson JF. Relation of haemoglobin levels in first and second trimesters to outcome of pregnancy. Lancet. 1986:1(8488):992-5.

16. Chumak EL, Grjibovski AM. Association between different levels of hemoglobin in pregnancy and pregnancy outcomes: a registry-based study in Northwest Russia. Int J Circumpol Heal. 2011;70(5):457-9.

17. Scanlon KS, Yip R, Schieve LA, Cogswell ME. High and low hemoglobin levels during pregnancy: differential risks for preterm birth and small for gestational age. Obstet Gynecol. 2000:96(5 Pt 1):741-8, doi:10.1016/ s0029-7844(00)00982-0.

18. von Tempelhoff GF, Heilmann L, Rudig L, Pollow K, Hommel G, Koscielny J. Mean maternal second-trimester hemoglobin concentration and outcome of pregnancy: a population-based study. Clin Appl Thromb Hemost. 2008; 14(1):19-28. doi:10.1177/1076029607304748.

19. Gholamreza V. Anemia in north of Iran (south-east of Caspian Sea). Pak J Biol Sci. 2007:10(10):1703-7.

20. Lund CJ, Donovan JC. Blood volume during pregnancy. Significance of plasma and red cell volumes. Am J Obstet Gynecol. 1967:98(3):394-403.

21. Thomsen JK, Fogh-Andersen N, Jaszczak P. Atrial natriuretic peptide, blood volume, aldosterone, and sodium excretion during twin pregnancy. Acta Obstet Gynecol Scand. 1994;73(1):14-20. doi:10.3109/00016349409013386.
22. Brown MA, Gallery ED. Volume homeostasis in normal pregnancy and pre-eclampsia: physiology and clinical implications. Bailliere's Clin Obstet Gynaecol. 1994;8(2):287-310.

23. Ouzounian JG, Elkayam U. Physiologic changes during normal pregnancy and delivery. Cardiol Clin. 2012;30(3):317-29. doi:10.1016/j.ccl.2012.05.004.

24. Whittaker PG, Macphail S, Lind T. Serial hematologic changes and pregnancy outcome. Obstet Gynecol. 1996;88(1):33-9. doi:10.1016/0029-7844(96)00095-6.

25. Amburgey OA, Ing E, Badger GJ, Bernstein IM. Maternal hemoglobin concentration and its association with birth weight in newborns of mothers with preeclampsia. J Matern Fetal Neonatal Med. 2009;22(9):740-4. doi:10.3109/14767050902926947.

26. Salas SP, Rosso P. Plasma volume, renal function, and hormonal levels in pregnant women with idiopathic fetal growth restriction or preeclampsia. Hypertens Pregnancy. 1998;17(1):69-79. doi:10.3109/10641959809072239.

27. Pena-Rosas JP, Viteri FE. Effects and safety of preventive oral iron or iron + folic acid supplementation for women during pregnancy. Cochrane Database Syst Rev. 2009;4:CD004736. doi:10.1002/14651858.CD004736.pub3.

28. Haider BA, Olofin I, Wang M, Spiegelman D, Ezzati M, Fawzi WW, et al. Anaemia, prenatal iron use, and risk of adverse pregnancy outcomes: systematic review and meta-analysis. BMJ. 2013;346:f3443. doi:10.1136/bmj.f3443.

29. Pena-Rosas JP, De-Regil LM, Dowswell T, Viteri FE. Daily oral iron supplementation during pregnancy. Cochrane Database Syst Rev. 2012; 12(12):CD004736. doi:10.1002/14651858.CD004736.pub4.

30. Rioux FM, LeBlanc CP. Iron supplementation during pregnancy: what are the risks and benefits of current practices? Applied physiology, nutrition, and metabolism. Physiol Appl Nutr Metab. 2007:32(2):282-8. doi:10.1139/H07-012.

31. Pourshams A, Saadatian-Elahi M, Nouraie M, Malekshah AF, Rakhshani N, Salahi R, et al. Golestan cohort study of oesophageal cancer: feasibility and first results. Br J Cancer. 2005;92(1):176-81. doi:10.1038/sj.bjc.6602249.

\section{Submit your next manuscript to BioMed Central and we will help you at every step:}

- We accept pre-submission inquiries

- Our selector tool helps you to find the most relevant journal

- We provide round the clock customer support

- Convenient online submission

- Thorough peer review

- Inclusion in PubMed and all major indexing services

- Maximum visibility for your research

Submit your manuscript at www.biomedcentral.com/submit 